\title{
A cohort mortality study of lead-exposed workers in the USA, Finland and the UK
}

\author{
Kyle Steenland, ${ }^{1}$ Vaughn Barry, ${ }^{1}$ Ahti Anttila, ${ }^{2}$ Markku Sallmén, ${ }^{3}$ Damien McElvenny, ${ }^{4}$ \\ AC Todd, ${ }^{5}$ Kurt Straif ${ }^{6}$
}

${ }^{1}$ Rollins School PubHealth, Emory University, Atlanta, USA ${ }^{2}$ Finnish Cancer Registry, Helsinki, Finland

${ }^{3}$ Finnish Institute of Occupational Health, Work, Environment, Helsinki, Finland ${ }^{4}$ Insitute of Occupational Medicine, Edinburgh, UK ${ }^{5}$ Icahn School of Medicine at Mount Sinai, New York, USA ${ }^{6}$ International Agency for Research on Cancer (IARC), Lyon, France

\section{Correspondence to}

Dr Kyle Steenland, Rollins School PubHealth, Emory University, Atlanta 30322, USA; nsteenl@emory.edu

Received 15 January 2017 Revised 30 March 2017 Accepted 2 May 2017 Published Online First 25 May 2017

\section{ABSTRACT}

Objectives To investigate further whether inorganic lead is a carcinogen among adults, or associated with increased blood pressure and kidney damage, via a large mortality study.

Methods We conducted internal analyses via Cox regression of mortality in three cohorts of lead-exposed workers with blood lead (BL) data (USA, Finland, UK), including over 88000 workers and over 14000 deaths. Our exposure metric was maximum BL. We also conducted external analyses using country-specific background rates.

Results The combined cohort had a median BL of $26 \mu \mathrm{g} / \mathrm{dL}$, a mean first-year BL test of 1990 and was $96 \%$ male. Fifty per cent had more than one BL test (mean 7). Significant $(p<0.05)$ positive trends, using the log of each worker's maximum BL, were found for lung cancer, chronic obstructive pulmonary disease (COPD), stroke and heart disease, while borderline significant trends $(0.05 \leq p \leq 0.10)$ were found for bladder cancer, brain cancer and larynx cancer. Most results were consistent across all three cohorts. In external comparisons, we found significantly elevated SMRs for those with $\mathrm{BLs}>40 \mu \mathrm{g} / \mathrm{dL}$; for bladder, lung and larynx cancer; and for COPD. In a small subsample of the US cohort $(n=115)$ who were interviewed, we found no association between smoking and $\mathrm{BL}$.

Conclusions We found strong positive mortality trends, with increasing BL level, for several outcomes in internal analysis. Many of these outcomes are associated with smoking, for which we had no data. A borderline trend was found for brain cancer, not associated with smoking.

\section{INTRODUCTION}

With the worldwide elimination of leaded gasoline, lead levels have dropped considerably in the environment and in the blood of the world population. ${ }^{2}{ }^{2}$ Nonetheless, lead remains a relatively common environmental and occupational exposure. For example, the US OSHA estimates that approximately 804000 workers in general industry, and an additional 838000 workers in construction, are currently potentially exposed to lead (https:// www.osha.gov/SLTC/lead/). This represents about $2 \%$ of the male workforce; most exposed workers are male (in 2012, the National Institute of Occupational Safety and Health (NIOSH) estimated that $92 \%$ of workers with blood lead (BL) levels above $10 \mu \mathrm{g} / \mathrm{dL}$, ie, occupational levels, were male, see https://www.cdc.gov/mmwr/preview/mmwrhtml/ mm6254a4.htm?s_cid $=$ mm6254a4_w). However,

\section{What this paper adds}

- Inorganic lead is considered a probable carcinogen by the International Agency for Research on Cancer (IARC), and adult lead exposure is known to raise blood pressure, and suspected of increasing rates of heart disease and stroke.

- We have analyzed mortality among 88000 workers with data on blood lead levels in three countries, with 14000 deaths, and a median maximum blood lead of $26 \mu \mathrm{g} / \mathrm{dL}$.

- Significant $(p<0.05)$ positive trends were found between blood lead levels and lung cancer, chronic obstructive pulmonary disease (COPD), stroke and heart disease, whereas borderline significant trends $(0.05<=p<=0.10)$ were found for bladder cancer, brain cancer and larynx cancer. Many of these outcomes are associated with smoking, for which we had little or no data. In a small sub sample of the US cohort $(n=115)$ who were interviewed, we found no association between smoking and maximum blood lead. On theoretical and a priori grounds, we do not think it is likely that confounding by smoking can explain our positive findings.

this may be an underestimate of current exposure prevalence, and is likely to underestimate the prevalence of lead exposure in the past. The last systematic survey of US workers took place in the 1980s. At that time, the NIOSH estimated that more than 3 million workers in the USA were potentially exposed to lead, ${ }^{3}$ representing at the time about $5 \%$ of the male workforce.

Both the International Agency for Research on Cancer (IARC) and the National Toxicology Program have concluded that inorganic lead is a probable human carcinogen, based primarily on evidence of the impacts of lead exposure on lung and stomach cancers and some suggestion of an effect on brain cancer. ${ }^{45}$

Lead exposure has been associated with modest increases in blood pressure, which may increase risk of stroke or heart disease. A meta-analysis of 31 studies by Nawrot et $a l^{6}$ found that most showed a positive association between $\mathrm{BL}$ and blood pressure after controlling for age: a doubling of BL was associated with a $1.0 \mathrm{~mm}$ rise in systolic pressure (95\% CI 0.5 to 1.4 ) and a $0.6 \mathrm{~mm} \mathrm{Hg}$ increase in 
diastolic pressure $(95 \% \mathrm{CI} 0.4$ to 0.8$)$. Increased blood pressure is a risk factor for stroke and heart disease, but information on these outcomes in relation to lead exposure is limited in the current literature. In a review of articles concerning lead and the risk of cardiovascular disease (CVD), Navas-Acien $e t a l^{7}$ found that overall there was insufficient epidemiological data to draw conclusions. A subsequent study of 868 US men in the Normative Aging Study, ${ }^{8}$ with past exposure to background lead levels, found strong positive trends between baseline bone lead and CVD but not baseline BL. Navas-Acien et $a l^{9}$ found a relationship between bone lead and increased blood pressure. These findings suggested that the cumulative exposure to higher blood levels in the past, reflected by the bone lead, might have a damaging cardiovascular effect not reflected by short-term exposure at baseline as assessed by BL. The Global Burden of Disease $2013^{10}$ has used (1) the estimated BL and bone lead across countries, (2) the relationship between bone lead and blood pressure from, ${ }^{9}$ and (3) the estimated relationship between blood pressure and both heart disease and stroke, to estimate a burden of disease from lead. They have estimated that BL levels above background are responsible for 850000 deaths, due to increased stroke and heart disease stemming from increased blood pressure. ${ }^{10}$ More detailed global burden of disease (GBD) analyses of stroke indicated that $7 \%$ of stroke worldwide was attributable to BL levels above $20 \mu \mathrm{g} / \mathrm{dL} .{ }^{11}$

Lead exposure is also associated with kidney disease. A comprehensive review of lead-related nephrotoxicity concluded that lead contributes to nephrotoxicity, even at BL levels below $5 \mu \mathrm{g} / \mathrm{dL}$, especially in people with other illnesses such as hypertension and diabetes. ${ }^{12}$ However, occupational mortality studies of lead-exposed workers have not consistently shown associations with kidney disease, which is a relatively rare cause of death.

To further investigate these associations, we have conducted a pooled analysis for mortality among three large cohort of workers with documented BL levels $(n=88000)$. These workers were enrolled in surveillance programmes in the USA, the UK and Finland, which measured inorganic lead in their blood. The pooled analysis allows increased power to observe exposureoutcome relationships. Furthermore, follow-up of the Finnish cohort has been extended 25 years, and the results have not been previously published. The documented BL levels among these workers provide data on body burden, which avoids some of the uncertainty of whether workers were actually exposed to lead, which occurs when exposure is estimated based on job title or a job-exposure matrix.

\section{METHODS}

\section{Cohorts}

The US cohort of 58000 male workers was assembled from the Adult Blood Lead Surveillance (ABLES) programme, sponsored by NIOSH. ABLES started collecting state-level data on BL levels in 1987 , starting with 4 states and increasing up to 41 states in 2012. ${ }^{13}$ States monitored testing laboratories to collect their data. Initially states collected data only on those with $\geq 25 \mu \mathrm{g} /$ $\mathrm{mL}$, but over time some states began to collect data on lower levels. BL levels were measured at different times in different states, but generally started in the early 1990s and went through 2007. Data on industry were collected in only some states, for those with $\geq 25 \mu \mathrm{g} / \mathrm{dL}$ blood levels, amounting to about $10 \%$ of ABLES subjects. Among those, $62 \%$ were in manufacturing, $10 \%$ in construction, $7 \%$ in metal mining, $1 \%$ in scrap metal and $20 \%$ in other industries. We included data from 11 states which had the majority of the ABLES data. We conducted mortality follow-up through 2010. Results of this follow-up have been published. ${ }^{14}$

The Finnish cohort of 21000 workers (12\% women) was created from those with documented BL in the period 1973-1983, based on laboratory reports and employer data. Finnish labour law mandated that if the BL of any worker in the workplace exceeded $42 \mu \mathrm{g} / \mathrm{dL}$, then all workers in that workplace should have their BL measured. Those with the most blood tests came from the battery industry, lead smelting, metal foundries, railroad machine shops and chemical factories. Those monitored for non-occupational reasons were excluded. The cohort was originally followed through 1988. ${ }^{15}{ }^{16}$ Follow-up has now been extended through 2013.

The UK cohort numbered 9000 (15\% women), and has been followed through 2011. Results of follow-up have been recently published. ${ }^{17}$ The cohort had BL levels measured in the period 1975-1979, as part of an effort at that time to conduct a census of all workers exposed to lead. The principal industrial sectors included pottery/glaze (14\%), lead battery (12\%), lead smelting $(10 \%)$ and demolition/scrap metal (9\%).

Cohort members were exposed in a large number of different occupations and industries in each country. The subjects in these cohorts were exposed almost exclusively occupationally, although in the US cohort there were a small number of men exposed recreationally in firing ranges.

\section{Exposure data}

The exposure data consisted of BL tests, conducted under occupational surveillance programmes. Details are available in the original publications. ${ }^{14-17}$ Complete work histories were not available, nor were data on any demographic variables beside birth date and gender. Half of the combined cohort had only one BL test, while the other half with more than one test had a median of four tests. For descriptive data, we report means when the data are normally distributed, and medians (or both) otherwise.

When a worker had multiple blood measurements, these were available for the USA and Finland, but for the UK we had only the maximum, the minimum and the number of measurements. We used the maximum BL as the principal exposure metric. This choice was motivated by two factors. One, generally when more than one BL measurement was available, they tended to be similar to each other, so the maximum was not far from the mean (see data below). Second, absent any accurate measure of cumulative exposure, we believed that the maximum BL was likely to be a reasonable choice for the most biologically relevant measure to predict future disease risk.

We calculated the intraclass correlation coefficient for workers with more than one blood test, that is, the proportion of the variance between workers, out of the total variance (the sum of between and within variances). For the UK, in which we did not have data on all BL measurements, but only the mean, the maximum and the number of measurements, we estimated the variance of the mean, for each worker with multiple tests, by (1) estimating the $\log$ (minimum) assuming symmetry with $\log (\max )$, and (2) using the range/ 4 of logged values as an estimate of the SD on log scale, then (3) converting to original unlogged scale. ${ }^{18}$

Here we have assumed that BL measurements were reasonably comparable across countries. However, there is some uncertainty here. A panel of industrial hygienists analysing this question was unable to reach a definitive conclusion about this point, ${ }^{19}$ and recommended inclusion of a variable for 'country' be included in analyses, which we have done. 


\section{Mortality analyses}

Person-time began at time of first BL test, and continued until the end of follow-up, death or year of emigration. We conducted internal analyses for different mortality outcomes via Cox regression (SAS PHREG, V. 9.22, http://support.sas.com/en/supporthome.html), with age as the time variable, while controlling for decade of year of birth, gender and country, and using the full risk set. Definition of different disease categories was made according to the groupings used by the NIOSH life table (see footnotes to tables 3 and 4). ${ }^{20}{ }^{21}$ We tested the proportional hazard assumption for exposure (equivalent to testing an interaction between exposure (BL level) and age), which was not violated. We also tested for interaction between BL level and country. We did not conduct lagged analyses as the true time of first exposure was unknown. We conducted both categorical analyses and continuous analyses. Categorical analyses used $<20 \mu \mathrm{g} / \mathrm{dL}$ maximum $\mathrm{BL}$ as the referent, and included categories 20-29, 30-39 and $40+\mu \mathrm{g} / \mathrm{dL}$. The UK data had only $1 \%$ of subjects with $<10 \mu \mathrm{g} /$ $\mathrm{dL}$, motivating the use of $<20 \mu \mathrm{g} / \mathrm{dL}$ as the referent. Furthermore, several authors have recently called for lowering currently permissible occupational BL levels $(40 \mu \mathrm{g} / \mathrm{dL}$ in many countries) to $20 \mu \mathrm{g} / \mathrm{dL}$, that is, under the assumption that the latter level is a reasonably safe level. ${ }^{22} 23$ The American College of Occupational and Environmental Medicine recently called for removal of workers from exposure when their BL levels exceed $20 \mu \mathrm{g} /$ dL. ${ }^{2}$ Currently, the US Occupational Safety and Health Administration requires removal of workers from exposure only when BL levels exceed $50 \mu \mathrm{g} / \mathrm{dL}$ (construction) or $60 \mu \mathrm{g} / \mathrm{dL}$ (general industry), and allows them to return only when their BL drops below $40 \mu \mathrm{g} / \mathrm{dL} \quad$ (https://www.osha.gov/pls/oshaweb/owadisp. show_document?p_id=10033\&p_table=STANDARDS).

For two countries where we had data on multiple tests per person (Finland and USA), we also ran analyses using time-dependent maximum BL. Results were virtually identical for these two countries to analyses using time-independent maximum BL. Therefore, for simplicity, and given that only time-independent maximum BL was available for the UK, we used time-independent maximum BL for all analyses. We tested for continuous trends using either maximum BL or its natural log. As the log term tended generally to fit the data better, we report trend tests using only the log of maximum BL.

We conducted external analyses via SMRs, using country-specific national mortality rates, stratified by 5 -year age and calendar time categories, using the NIOSH Life Table Analysis System. ${ }^{20}$ Again, we used the International Classification of Disease (ICD) groupings for different mortality outcomes from the NIOSH life table, to create disease-specific external rates. ${ }^{21}$

\section{Cross-sectional data on bone lead}

We have studied tibia lead in 115 US cohort members, as a way to determine whether maximum $\mathrm{BL}$ in the past is correlated with current bone lead, the latter being a measure of cumulative absorbed dose. Cohort members living near New York City were invited to undergo a tibia lead measurement, conducted at Icahn School of Medicine at Mount Sinai University by A.C. Todd, PhD. The study is designed to assess bone lead among 200 US cohort members; we report here preliminary analyses of the first 115 tested. In addition to bone lead, we report on smoking habits of the men tested.

K-shell X-ray fluorescence has been used to measure lead in bone in numerous studies over the past 40 years. The particular method we used has been described by Todd et $a l,{ }^{24}$ and shown to be repeatable in the field. ${ }^{25}$ The procedure takes about $30 \mathrm{~min}$. In brief, the $88.034 \mathrm{keV} \gamma$-rays from ${ }^{109} \mathrm{Cd}$ are used to fluoresce the K-shell X-rays of lead. The ${ }^{109} \mathrm{Cd} \gamma$-rays can also undergo elastic scatter off an atom of primarily calcium and phosphorus in bone. The $\gamma$-rays that escape the body after they have interacted, and which are head in the direction of the radiation detector, can be recorded by the spectroscopy system which yields an energy distribution, or spectrum (number of photons of energy that lies in a particular energy range vs the mid-point of that energy range) of the recorded photons. The spectrum is then 'fitted' using a non-linear, least-squares technique with a mathematical function to extract the amplitudes of the X-ray and elastic scatter peaks that rise above the background continuum of scattered photons. The ratio of the X-ray to elastic peaks is the response of the system and is regressed, for each X-ray peak under analysis, against the lead concentration of the calibration standards to produce a calibration line. The signal from a subject measured in vivo is compared with the established calibration line for each lead X-ray to be analysed to obtain one or more estimates of the subject's bone lead concentration

\section{RESULTS}

Table 1 provides a summary of cohort statistics. The US cohort was assembled later and was considerably younger than the other two cohorts.

Table 2 provides summary data on the BL tests, including some data on those with multiple BL measurements $50 \%$ of the combined cohort). The intraclass correlation coefficient (proportion of variance between subjects out of total variance) for those with multiple measurements was 0.86 , indicating that the variance with a person's measurement was much less than the variance between the means of different workers.

Those in higher maximum BL category had somewhat longer time since first BL test; this time increased from 17 to 22 years from the lowest to higher category. They had an earlier first BL test (1988 for those $>40 \mu \mathrm{g} / \mathrm{dL}$ vs 1993 for those with $<20 \mu \mathrm{g}$ / $\mathrm{dL}$ ) and more BL tests (increasing trend, median 1.5 tests for those in the $<20 \mu \mathrm{g} / \mathrm{dL}$ category, 4.0 tests for those in the $>40 \mu \mathrm{g} /$ dL category). They were also born somewhat earlier (mean 1953 for $<20 \mu \mathrm{g} / \mathrm{dL}$, mean 1948 for those in the $>40 \mu \mathrm{g} / \mathrm{dL}$ category).

Table 3 gives the results for selected non-malignant causes of a priori interest (all deaths, heart disease, stroke, chronic

Table 1 Descriptive data for three cohorts

\begin{tabular}{|c|c|c|c|c|c|c|c|c|}
\hline Country & Total & Person-years & $\begin{array}{l}\text { Deaths } \\
\text { (\% deaths in } \\
\text { cohort) }\end{array}$ & Cancer deaths & $\begin{array}{l}\text { Mean year first } \\
\text { follow-up* }\end{array}$ & $\begin{array}{l}\text { Last year } \\
\text { follow-up }\end{array}$ & Mean year of birth & Female (\%) \\
\hline USA & 58313 & 732657 & 3339 (6\%) & 992 & 1997 & 2010 & 1958 & 0 \\
\hline UK & 9122 & 272680 & 3477 (38\%) & 1103 & 1976 & 2011 & 1939 & 15 \\
\hline Finland & 20752 & 656209 & 7155 (34\%) & 1786 & 1977 & 2013 & 1943 & 12 \\
\hline Total & 88187 & 1661546 & 14107 & 3881 & 1990 & 2011 & 1953 & 4 \\
\hline
\end{tabular}

*Year of first blood lead test. 
Table 2 Distribution of blood lead levels

\begin{tabular}{|c|c|c|c|c|c|c|c|c|c|}
\hline Country & $\begin{array}{l}\text { Max blood lead } \\
<10, \mu \mathrm{g} / \mathrm{dL}(\%)\end{array}$ & $\begin{array}{l}\text { Max blood } \\
\text { lead } \\
10 \text { to }<20 \text {, } \\
\mu \mathrm{g} / \mathrm{dL}(\%)\end{array}$ & $\begin{array}{l}\text { Max blood } \\
\text { lead } \\
20 \text { to }<30 \text {, } \\
\mu \mathrm{g} / \mathrm{dL}(\%)\end{array}$ & $\begin{array}{l}\text { Max blood } \\
\text { lead } \\
30 \text { to }<40 \text {, } \\
\mu \mathrm{g} / \mathrm{dL}(\%)\end{array}$ & $\begin{array}{l}\text { Max blood } \\
\text { lead } \\
40+, \mu g / \\
d L(\%)\end{array}$ & $\begin{array}{l}\text { Median max } \\
\text { blood lead } \\
\mu \mathrm{g} / \mathrm{dL}(\%)\end{array}$ & $\begin{array}{l}\text { Mean/median } \\
\text { blood leads } \\
\text { per person }\end{array}$ & $\begin{array}{l}\text { Subjects with more } \\
\text { than one blood } \\
\text { lead }(\%)\end{array}$ & $\begin{array}{l}\text { Intraclass correlation } \\
\text { coefficient } \\
\text { (\% total variance due to } \\
\text { variance between) for } \\
\text { those with more than one } \\
\text { blood test }\end{array}$ \\
\hline USA & 21 & 18 & 21 & 20 & 20 & 26 & $4 / 2$ & 51 & 0.77 \\
\hline UK & 1 & 9 & 17 & 16 & 58 & 48 & $4 / 2$ & 60 & 0.94 \\
\hline Finland & 16 & 41 & 22 & 9 & 11 & 19 & $3 / 1$ & 41 & 0.85 \\
\hline Total & 17 & 23 & 21 & 17 & 22 & 26 & $4 / 1$ & 50 & 0.86 \\
\hline
\end{tabular}

obstructive pulmonary disease (COPD) and kidney disease). There are positive statistically significant trends for all these, except non-malignant kidney disease where the uppermost category showed a 54\% excess, but this finding was limited by small numbers. Statistically significant trends are driven by both the increased trends in HRs and the large numbers of deaths for these causes.

For cancers, we tested for trend for 13 malignant cancers with appreciable numbers (bladder, brain (benign included), breast (women only), oesophageal, kidney, larynx, lung, pharynx, stomach, leukaemia, Hodgkin's disease, multiple myeloma and non-Hodgkin's lymphoma). All trends were positive (increasing rate with increasing $\mathrm{BL}$ ), although not necessarily statistically significant, with the exception of stomach cancer and leukaemia. Table 4 shows the categorical results and trend tests for four cancers for which the $\mathrm{p}$ value for positive trend was $<0.10$, two of which were of a priori interest (lung, brain), and two of which were not (bladder, larynx). Table 4 also shows data for two cancers of a priori interest which showed little trend; stomach cancer ( $\mathrm{p}$ for trend $0.93,195$ deaths) and kidney cancer ( $\mathrm{p}$ for trend $0.79,128$ deaths).

There were generally few interactions by country. For outcomes with positive trends in the no-interaction models, we subsequently found significant interactions for lung cancer (UK positive trend, $\mathrm{p}=0.14 ;$ USA/Finland positive trends, $\mathrm{p}<0.0001$ ) and stroke (USA positive trend, $\mathrm{p}=0.13$; UK/Finland trends, $\mathrm{p}=0.0002$ and $\mathrm{p}=0.0009$, respectively).

Results for SMRs for all three countries combined (using national rates as the referent) are shown in table 5 , for causes for which rates were available across all three countries. Rates were available from time of first blood testing in all countries. For those in thie highest BL category, there are significant $(\mathrm{p}<0.05)$ excesses for bladder cancer, lung cancer, COPD and larynx cancer, and deficits for kidney cancer, multiple myeloma and leukaemia. There was no excess for brain cancer, an a priori outcome of interest, based only on malignant cases (external rates were not available for benign brain cancer). Deaths from transportation accidents are linked to lower socioeconomic status (SES), ${ }^{26}$ but did not show an excess versus the general population.

In the cross-sectional analyses of the subsample of US cohort members $(n=115)$, the average age was 61 (range 39-85), 85\% were white, $14 \%$ Hispanic and $40 \%$ had a high school education or less. The smoking habits were as follows: current smokers (14\%), former smokers (44\%) and never smokers (42\%). Maximum BL was distributed as follows: $33 \%<20 \mu \mathrm{g} / \mathrm{dL}, 42 \%$ $20-39 \mu \mathrm{g} / \mathrm{dL}$ and $25 \%>40 \mu \mathrm{g} / \mathrm{dL}$. Smoking history measured via pack-years was not correlated with maximum BL (Spearman correlation $r=0.01)$. Ever smokers and never smokers did not

Table 3 Categorical and continuous results of mortality analyses by blood lead category for selected non-malignant causes of death

\begin{tabular}{|c|c|c|c|c|c|}
\hline Cause & $\begin{array}{l}\text { Number of deaths by } \\
\text { lead category }\end{array}$ & Lead category, $\mu \mathrm{g} / \mathrm{dL} t$ & $H R^{*}$ & $95 \% \mathrm{Cl}$ & $\begin{array}{l}\text { Coefficient for In max } \\
\text { blood lead; } p \text { value for } \\
\text { test for trend }\end{array}$ \\
\hline \multirow[t]{3}{*}{ All deaths, $n=13971$} & 2833 & 20 to $<30$ & 1.15 & 1.10 to 1.21 & $1.17 ; p<0.0001$ \\
\hline & 1963 & 30 to $<40$ & 1.21 & 1.15 to 1.28 & \\
\hline & 4451 & $40+$ & 1.43 & 1.36 to 1.50 & \\
\hline \multirow{3}{*}{$\begin{array}{l}\text { Chronic kidney disease, } \\
n=62^{*}\end{array}$} & 8 & 20 to $<30$ & 0.70 & 0.30 to 1.65 & $1.25 ; p=0.25$ \\
\hline & 7 & 30 to $<40$ & 0.68 & 0.27 to 1.70 & \\
\hline & 30 & $40+$ & 1.54 & 0.77 to 3.08 & \\
\hline \multirow[t]{3}{*}{ COPD, $n=543^{*}$} & 107 & 20 to $<30$ & 1.43 & 1.10 to 1.86 & $1.39 ; p<0.0001$ \\
\hline & 72 & 30 to $<40$ & 1.31 & 0.96 to 1.78 & \\
\hline & 236 & $40+$ & 1.84 & 1.42 to 2.38 & \\
\hline \multirow{3}{*}{$\begin{array}{l}\text { Ischaemic heart disease, } \\
\mathrm{n}=3227^{*}\end{array}$} & 657 & 20 to $<30$ & 1.14 & 1.04 to 1.26 & $1.22 ; p<0.0001$ \\
\hline & 413 & 30 to $<40$ & 1.16 & 1.03 to 1.31 & \\
\hline & 1048 & $40+$ & 1.41 & 1.28 to 1.57 & \\
\hline \multirow[t]{3}{*}{ Stroke, $n=871^{*}$} & 181 & 20 to $<30$ & 1.24 & 1.03 to 1.50 & $1.23 ; p=0.0002$ \\
\hline & 130 & 30 to $<40$ & 1.49 & 1.20 to 1.85 & \\
\hline & 261 & $40+$ & 1.41 & 1.16 to 1.72 & \\
\hline
\end{tabular}

*Kidney disease ICD 9 codes 582-583 585-587, ICD10 codes N01 N03 N05 N07 N14.0-N14.3 N15.0 N18 N19 N26; COPD ICD 9 codes 490-492 496, ICD 10 codes J40-J44; heart disease ICD9 codes 410-414, ICD10 codes I20-I22 I24-I25 I51.3 I51.6; stroke ICD9 codes 430-438, ICD10 codes G45 I60-I64 I67 I69.

${ }^{\dagger}$ Referent is $<20 \mu \mathrm{g} / \mathrm{dL}$ maximum blood lead, adjusted for gender, birth year decade, country. 
Table 4 Categorical and continuous results of mortality by blood lead category for selected cancers*

\begin{tabular}{|c|c|c|c|c|c|}
\hline Cause & $\begin{array}{l}\text { Number of deaths by } \\
\text { lead category }\end{array}$ & Lead category, $\mu \mathrm{g} / \mathrm{dL}$ & HRt & $95 \% \mathrm{Cl}$ & $\begin{array}{l}\text { Coefficient for In max blood lead; } \\
\text { p value for test for trend }\end{array}$ \\
\hline \multirow{3}{*}{$\begin{array}{l}\text { Bladder cancer } \\
\mathrm{n}=96\end{array}$} & 15 & 20 to $<30$ & 1.02 & 0.54 to 1.93 & $1.35 ; p=0.06 \ddagger$ \\
\hline & 14 & 30 to $<40$ & 1.40 & 0.71 to 2.76 & \\
\hline & 40 & $40+$ & 1.86 & 1.04 to 3.33 & \\
\hline \multirow{3}{*}{$\begin{array}{l}\text { Brain cancer (including } \\
\text { benign) } n=111\end{array}$} & 26 & 20 to $<30$ & 1.31 & 0.79 to 2.17 & $1.28 ; p=0.09 \ddagger$ \\
\hline & 14 & 30 to $<40$ & 1.05 & 0.55 to 1.99 & \\
\hline & 33 & $40+$ & 1.42 & 0.83 to 2.43 & \\
\hline \multirow{3}{*}{$\begin{array}{l}\text { Larynx cancer } \\
\mathrm{n}=39\end{array}$} & 6 & 20 to $<30$ & 1.21 & 0.41 to 3.54 & $1.54 ; p=0.09 \ddagger$ \\
\hline & 4 & 30 to $<40$ & 0.97 & 0.28 to 3.35 & \\
\hline & 21 & $40+$ & 2.69 & 1.07 to 6.76 & \\
\hline \multirow{3}{*}{$\begin{array}{l}\text { Lung cancer } \\
\mathrm{n}=1333\end{array}$} & 271 & 20 to $<30$ & 1.39 & 1.19 to 1.64 & $1.36 ; p=<0.0001 \ddagger$ \\
\hline & 214 & 30 to $<40$ & 1.54 & 1.29 to 1.84 & \\
\hline & 500 & $40+$ & 1.78 & 1.51 to 2.08 & \\
\hline \multirow{3}{*}{$\begin{array}{l}\text { Kidney cancer } \\
n=128\end{array}$} & 24 & 20 to $<30$ & 0.89 & 0.54 to 1.45 & $1.03 ; p=0.79$ \\
\hline & 9 & 30 to $<40$ & 0.50 & 0.24 to 1.03 & \\
\hline & 42 & $40+$ & 1.21 & 0.74 to 1.97 & \\
\hline \multirow{3}{*}{$\begin{array}{l}\text { Stomach cancer } \\
\mathrm{n}=195\end{array}$} & 57 & 20 to $<30$ & 1.62 & 1.13 to 2.32 & $0.99 ; p=0.93$ \\
\hline & 18 & 30 to $<40$ & 0.84 & 0.49 to 1.44 & \\
\hline & 53 & $40+$ & 1.09 & 0.70 to 1.67 & \\
\hline
\end{tabular}

*Bladder cancer ICD9 188-189, ICD10 C67-C68; brain cancer ICD9 191-192, ICD10 C47, C70-C72; larynx cancer ICD9 161, ICD10 C32; lung cancer ICD9 162, ICD10 C33-C34. tReferent is $<20 \mu \mathrm{g} / \mathrm{dL}$ maximum blood lead, adjusted for gender, birth year decade, country.

$\ddagger$ Cancers with trends $<0.10$ for $\ln (\max$ blood lead), and two a priori cancers (stomach, kidney).

differ with respect to their maximum bone lead $(\mathrm{p}=0.80)$. Linear regression analyses controlling for age, ethnicity and education did not change these null results. In linear regression analyses controlling for age, ethnicity and education, maximum BL was a strong positive predictor of bone lead $(\mathrm{p}=0.004)$ (model R-square 0.29 ). However, this positive trend was not monotonic, but driven by those with maximum $\mathrm{BL} \geq 40 \mu \mathrm{g} / \mathrm{dL}$. In analyses using quartile of maximum $\mathrm{BL}$, the estimated change in bone

Table 5 SMRs for cohort members by maximum blood lead category*

\begin{tabular}{|c|c|c|c|c|c|c|c|c|c|}
\hline \multirow[b]{2}{*}{ Cause } & \multicolumn{3}{|c|}{ Max blood lead $<20 \mu \mathrm{g} / \mathrm{m}^{3}$} & \multicolumn{3}{|c|}{ Max blood lead $20-39 \mu \mathrm{g} / \mathrm{m}^{3}$} & \multicolumn{3}{|c|}{ Max blood lead $>40 \mu \mathrm{g} / \mathrm{m}^{3}$} \\
\hline & Observed & SMR & $95 \% \mathrm{Cl}$ & Observed & SMR & $95 \% \mathrm{Cl}$ & Observed & SMR & $95 \% \mathrm{Cl}$ \\
\hline Bladder cancer & 27 & 0.84 & 0.52 to 1.14 & 30 & 0.83 & 0.53 to 1.13 & 55 & $1.54 \dagger$ & 1.13 to 1.88 \\
\hline Brain cancer & 39 & 0.78 & 0.54 to 1.03 & 40 & 0.84 & 0.58 to 1.10 & 33 & 0.93 & 0.61 to 1.20 \\
\hline Breast cancer & 18 & 0.57 & 0.31 to 0.83 & 21 & 1.04 & 0.60 to 1.49 & 16 & 1.11 & 0.56 to 1.57 \\
\hline Cerebrovascular disease & 300 & 0.82 & 0.73 to 0.91 & 314 & 0.99 & 0.88 to 1.10 & 263 & 0.99 & 0.87 to 1.09 \\
\hline COPD & 128 & 0.78 & 0.65 to 0.92 & 182 & 0.96 & 0.82 to 1.10 & 242 & $1.33+$ & 1.16 to 1.47 \\
\hline Oesophageal cancer & 36 & 0.88 & 0.59 to 1.17 & 48 & 0.93 & 0.67 to 1.19 & 55 & 1.07 & 0.79 to 1.32 \\
\hline Ischaemic heart disease & 1109 & 0.81 & 0.76 to 0.86 & 1075 & 0.85 & 0.80 to 0.90 & 1059 & 1.02 & 0.96 to 1.07 \\
\hline Kidney cancer & 47 & 0.65 & 0.46 to 0.83 & 31 & 0.54 & 0.35 to 0.72 & 28 & 0.73 & 0.46 to 0.97 \\
\hline Kidney disease & 17 & 0.84 & 0.44 to 1.24 & 17 & 0.58 & 0.30 to 0.85 & 31 & 1.19 & 0.77 to 1.55 \\
\hline Larynx cancer & 8 & 0.71 & 0.22 to 1.21 & 10 & 0.75 & 0.29 to 1.22 & 21 & $1.80 t$ & 1.03 to 2.46 \\
\hline Leukaemia & 49 & 1.14 & 0.82 to 1.45 & 41 & 0.91 & 0.63 to 1.18 & 25 & 0.69 & 0.42 to 0.92 \\
\hline Lung cancer & 350 & 0.90 & 0.81 to 1.00 & 490 & & 1.06 to 1.26 & 506 & $1.38 t$ & 1.26 to 1.48 \\
\hline Multiple myeloma & 21 & 0.80 & 0.46 to 1.14 & 22 & 0.88 & 0.51 to 1.25 & 12 & 0.60 & 0.26 to 0.89 \\
\hline Non-Hodgkins lymphoma & 52 & 0.95 & 0.69 to 1.20 & 32 & 0.60 & 0.39 to 0.81 & 36 & 0.87 & 0.59 to 1.12 \\
\hline Pharynx cancer & 6 & 0.47 & 0.09 to 0.85 & 8 & 0.56 & 0.17 to 0.96 & 13 & 1.13 & 0.52 to 1.66 \\
\hline Stomach cancer & 67 & 0.92 & 0.70 to 1.14 & 75 & 1.16 & 0.90 to 1.43 & 54 & 0.97 & 0.71 to 1.19 \\
\hline Accidents(transportation)‡ & 33 & 0.60 & 0.39 to 0.80 & 87 & 0.94 & 0.74 to 1.13 & 64 & 0.97 & 0.73 to 1.17 \\
\hline
\end{tabular}

*SMRs calculated using national rates for USA, UK and Finland, adjusted for age/gender/calendar time.

$\mathrm{tCl}$ excludes 1 .

$¥$ Restricted to the USA and UK, no rates available for Finland.

COPD, chronic obstructive pulmonary disease. 
lead for the second, third and fourth quartiles of BL versus the first was respectively $-1.7(\mathrm{p}=0.47),-3.6(\mathrm{p}=0.16)$ and +8.3 $(\mathrm{p}=0.004)(\mathrm{R}$-squared model 0.40$)$.

\section{DISCUSSION}

Our study was based on workers with lead exposure documented via BL tests. BL reflects short-term exposure, generally within the last few months. ${ }^{27}$ This cohort definition has both advantages and disadvantages. Without work history, we do not have a data on first exposure or length of work in a job potentially exposed to lead, making impossible analyses by duration or latency, or lagged exposure. On the other hand, for each individual worker we avoid the uncertainty arising from job-exposure matrices, regarding whether workers in specific jobs were actually exposed to lead, by having a measure of an internal dose.

Bone lead analyses on a subsample of the US cohort found that maximum BL was correlated with bone lead, the latter being a measure of cumulative dose, while the former represents exposure in the recent past (weeks to months). This correlation, however, was driven by those with the highest maximum BL levels, above $40 \mu \mathrm{g} / \mathrm{dL}$. This may reflect that those in the jobs with the greatest exposure intensity (as measured by BL) experienced the greatest cumulative exposure (as measured by the product of exposure intensity and exposure duration: bone lead). ${ }^{28}$ Data collection in this cross-sectional study is still underway and a larger sample size may shed further light on this question.

Strong positive trends were found in internal analyses for all causes, lung cancer, bladder cancer, larynx cancer, COPD, heart disease and stroke. A weak non-monotonic trend was found for brain cancer.

Regarding cancer, these findings for cancer are concordant with IARCs 2006 determination $^{4}$ that lung and brain cancer were two cancers more strongly associated with inorganic lead, but are not concordant regarding stomach cancer. Two studies since the IARC evaluation are worth nothing. Gwini et al ${ }^{29}$ studied cancer incidence among male Australian workers in a lead surveillance programme with a similar design to ours. There were 240 incident cancers; the only significant excesses were for liver and oesophageal cancers. However, only 95 of the 240 subjects with cancer had BL levels; of these 95, only 27 had levels at or above $30 \mu \mathrm{g} / \mathrm{dL}$. Hence, there is little information about specific cancer sites among men with high exposure in this cohort. Liao $e t a l^{30}$ studied cancer incidence among approximately 7000 lead-exposed men and women workers in two plants in Shanghai, comparing them with a large number of unexposed workers, and using a job-exposure matrix to classify workers into none, low, medium and high exposure to either lead dust or fumes. Overall, there were suggestions of an excess among exposed versus non-exposed workers for brain cancer (rate ratio (RR) 1.8, 0.704.28, 10 exposed cases) and kidney cancer (RR 1.4, (0.9-2.3), 17 exposed cases). Borderline significant exceses were found in high-exposed males only for lung and stomach cancer. Overall, our cancer findings are reasonably concordant with other findings for lung and brain cancer, but not for bladder and larynx cancer. The latter is rare and often not reported in occupational lead studies.

All of the outcomes we found to be elevated with higher exposure, with the exception of brain cancer, ${ }^{31}$ are associated with smoking, which raises the question of whether smoking habits confounded these internal analyses; we had no data on smoking. However, internal analyses of comparing workers with workers are generally less subject to confounding by smoking, compared with SMR analyses comparing workers with the general population. ${ }^{32}$ In particular, internal comparisons in which the uppermost category showed HRs of 1.8-2.7 (bladder, lung, larynx, bladder, COPD) are unlikely to be due to confounding by smoking under hypothetical or observed smoking differences between low and high-exposed workers. Earlier work has shown that for diseases which are strongly related to smoking (eg, lung cancer), observed smoking differences between low and high-exposed workers are likely to account for excesses of only $20 \%-40 \%$ due to confounding. ${ }^{33} 34$ In addition, other outcomes strongly associated with smoking, such as oesophageal cancer (trend test $\mathrm{p}=0.17,138$ deaths), or moderately associated, such as kidney cancer (trend test $\mathrm{p}=0.79,128$ deaths), did not show significantly positive trends. It might also be noted that in an earlier nested case-control study of lung cancer in the Finnish cohort, a study which had smoking data, smoking was not associated with BL level. ${ }^{16}$ Finally, in our subsample of US cohort members, we found no association between smoking habits and maximum BL levels.

Smoking is correlated with SES, which is in itself highly related to most causes of mortality. We had census-based data on SES from one cohort. We matched the Finnish data to census data to determine broad occupational category. Matching the cohort to the censuses of $1970,1975,1980,1985$ and 1990, 99\% of cohort had at least one match. Taking data from the last available census for each worker, the percentage of workers in the blue-collar category by category of BL (ie <10, 10-20, 20-30, $30-40$ and $40+\mu \mathrm{g} / \mathrm{dL}$ ) were $71 \%, 77 \%, 78 \%, 78 \%$ and $81 \%$, respectively, indicating some, but not dramatic, decrease in SES with higher lead exposure.

Confounding by other occupational exposures in the workplace is another possibility. Regarding occupational carcinogens, workers in our cohort were exposed to lead in many different jobs with many different possible co-exposures, making it less likely that any specific co-exposure to a carcinogen would be responsible for our observed associations with several cancers. On the other hand, dust exposure was likely to have been common to many lead-exposed jobs, and may have contributed to the COPD findings. We know of no prior evidence that lead exposure is associated with COPD. Data on such co-exposures were not available across all cohorts (for further discussion of this issue, see ${ }^{19}$ ).

On the other hand, despite potential confounding, there are some arguments for a causal role in lead for many of the outcomes for which we found associations. Other heavy metals are well known to cause lung cancer (nickel, chromium, cadmium, beryllium). Stroke and heart disease were a priori outcomes of interest due to lead's effect on blood pressure. Brain cancer was an outcome of a priori interest, given the prior findings for brain cancer incidence from the Finnish cohort, ${ }^{15}$ based on 26 incident cases with follow-up to 1990 . However, we know of no a priori reason to associate larynx cancer to metal exposure; occupational exposures associated with larynx cancer include asbestos, sulfuric acid and polycyclic aromatic hydrocarbons (PAHs). ${ }^{35} 36$

Non-malignant kidney disease, an outcome of a priori interest, did not show a significant positive trend with lead, although did show a 54\% (HR 1.54, 0.77-3.08) elevation in the highest category $(\geq 40 \mu \mathrm{g} / \mathrm{dL})$. Non-malignant kidney disease may be underascertained using underlying cause of death certificates (without reference to contributing causes), reducing power; one study in the USA showed that non-malignant kidney disease was four times more likely to appear as a contributing causes rather than an underlying cause. ${ }^{37}$ It should be noted that incident end-stage renal disease, in a separate analysis of the American cohort, ${ }^{38}$ showed an excess of $43 \%$ in the highest category 
$(\geq 51 \mu \mathrm{g} / \mathrm{dL}$, HR $1.43(1.01-1.85))$, for those with at least 5 years of follow-up.

External comparison analysis via SMRs, among those in the highest category $(\geq 40 \mu \mathrm{g} / \mathrm{dL})$, showed that a number of the excesses seen in internal analyses were also observed in comparison with the general population, i.e., for COPD, bladder cancer, larynx cancer and lung cancer. These are the outcomes which had the most pronounced trends in internal analyses. Other outcomes with positive trends in internal analyses, such as heart disease and stroke, may have been more affected by the healthy worker effect in the SMR analyses, occurring when comparing workers to the general population. The US cohort is young and particularly subject to the healthy worker effect, and is bigger than the combined size of the older Finnish and UK cohorts.

One main limitation to our data was our reliance on $\mathrm{BL}$, without a complete work history of lead-exposed jobs, precluding analyses by duration or latency. A second major limitation was the limited number of BL measurements, again precluding a complete picture of cumulative internal exposure. At the same time, the availability of BL for all cohort members was a strength, because we had documentation of lead exposure, and a reasonable way to rank subjects by level of exposureunder the assumption that the range of BLs for a given worker reflected their average exposure level. The other main strength of our data is the large sample size, permitting analyses of relatively rare outcomes.

In summary, findings from this cohort are suggestive of lead effects on several causes of mortality. Confounding by smoking and SES may be playing a role in some of these excesses, but are unlikely to explain them entirely. Planned future analyses of cancer incidence in these cohorts should provide additional information.

\section{Contributors All contributors meet the criteria for authorship.}

Funding Steenland worked on this project as part of his stay at IARC as a Visiting Scientist inthe summers of 2014 and 2015.

Competing interests None declared.

Ethics approval Emory University IRB: note, this is a record based study with no contact with study subjects.

Provenance and peer review Not commissioned; externally peer reviewed.

(c) Article author(s) (or their employer(s) unless otherwise stated in the text of the article) 2017. All rights reserved. No commercial use is permitted unless otherwise expressly granted.

\section{REFERENCES}

1 Tsai P, Hatfield T. Global benefits from the phase-out of leaded fuel. J Environ Health 2011;74:8-14.

2 Holland MG, Cawthon D. ACOEM Task Force on Blood lead levels. Workplace lead exposure. J Occup Environ Med 2016;58:e371-e374.

3 Staudinger K, Roth V, poisoning O. Am Fam Physician 1998;57:719-26.

4 IARC. Monographs on the evaluation of carcinogenic risks to humans, inorganic and Organic lead compounds, volume 87. IARC Lyon 2006 http://monographs.iarc.fr/ENG/ Monographs/vol87/.

5 National Toxicology Program, Report on carcinogens: lead and lead compounds, NTP 2004. http://ntp.niehs.nih.gov/ntp/roc/content/profiles/lead.pdf.

6 Nawrot TS, Thijs L, Den Hond EM, et al. An epidemiological re-appraisal of the association between blood pressure and blood lead: a meta-analysis. J Hum Hypertens 2002;16:123-31.

7 Navas-Acien A, Guallar E, Silbergeld EK, et al. Lead exposure and cardiovascular disease-a systematic review. Environ Health Perspect 2007;115:472-82.

8 Weisskopf MG, Jain N, Nie H, et al. A prospective study of bone lead concentration and death from all causes, cardiovascular diseases, and Cancer in the Department of Veterans Affairs Normative Aging Study. Circulation 2009;120:1056-64.

9 Navas-Acien A, Schwartz BS, Rothenberg SJ, et al. Bone lead levels and blood pressure endpoints: a meta-analysis. Epidemiology 2008;19:496-504.
10 GBD. Risk factors Collaborators.global, regional, and national comparative risk assessment of 79 behavioural, environmental and occupational, and metabolic risks or clusters of risks in 188 countries, 1990-2013: a systematic analysis for the global burden of disease study 2013. Lancet 2015:5:2287-323.

11 Feigin VL, Roth GA, Naghavi M, et al. Global burden of stroke and risk factors in 188 countries, during 1990-2013: a systematic analysis for the global burden of disease study 2013. Lancet Neurol 2016;15:913-24.

12 Ekong EB, Jaar BG, Weaver VM. Lead-related nephrotoxicity: a review of the epidemiologic evidence. Kidney Int 2006;70:2074-84.

13 Roscoe RJ, Ball W, Curran JJ, et al. Adult blood lead epidemiology and surveillance-United States, 1998-2001. MMWR Surveill Summ 2002;51:1-10.

14 Chowdhury R, Sarnat SE, Darrow L, et al. Mortality among participants in a lead surveillance program. Environ Res 2014;132:100-4.

15 Anttila A, Heikkilä P, Nykyri E, et al. Risk of nervous system Cancer among workers exposed to lead. J Occup Environ Med 1996;38:131-6.

16 Anttila A, Heikkilä P, Pukkala E, et al. Excess lung Cancer among workers exposed to lead. Scand I Work Environ Health 1995;21:460-9.

17 McElvenny DM, Miller BG, MacCalman LA, et al. Mortality of a cohort of workers in Great Britain with blood lead measurements. Occup Environ Med 2015;72:625-32.

18 Hozo SP, Djulbegovic B, Hozo I. Estimating the mean and variance from the median, range, and the size of a sample. BMC Med Res Methodol 2005;5:13.

19 Sleeuwenhoek A, van Tongeren M, Cherrie J, et al; International Pooled Study of cohorts of workers with blood lead measurements: exposure Assessment. Edinborough: Institute of Occupational Medicine, 2016. http://www.iom-world.org/.

20 Schubauer-Berigan MK, Hein MJ, Raudabaugh WM, et al. Update of the NIOSH life table analysis system: a person-years analysis program for the windows computing environment. Am J Ind Med 2011;54:915-24.

21 Robinson CF, Schnorr TM, Cassinelli RT, et al. Tenth revision U.S. mortality rates for use with the NIOSH Life Table Analysis System. J Occup Environ Med 2006;48:662-7.

22 Schwartz BS, Hu H. Adult lead exposure: time for change. Environ Health Perspect 2007;115:451-4.

23 Kosnett MJ, Wedeen RP, Rothenberg SJ, et al. Recommendations for medical management of adult lead exposure. Environ Health Perspect 2007;115:463-71.

24 Todd AC, McNeill FE, Palethorpe JE, et al. In vivo X-ray fluorescence of lead in bone using K X-ray excitation with $109 \mathrm{Cd}$ sources: radiation dosimetry studies. Environ Res 1992;57:117-32

25 Todd AC, Ehrlich RI, Selby P, et al. Repeatability of tibia lead measurement by X-Ray fluorescence in a battery-making workforce. Environ Res 2000;84:282-9.

26 Steenland K, Halperin W, Hu S, et al. Deaths due to injuries among employed adults: the effects of socioeconomic class. Epidemiology 2003;14:74-9.

$27 \mathrm{Hu} \mathrm{H}$, Shih R, Rothenberg S, et al. The epidemiology of lead toxicity in adults: measuring dose and consideration of other methodologic issues. Environ Health Perspect 2007;115:455-62.

28 Barbosa F, Tanus-Santos JE, Gerlach RF, et al. A critical review of biomarkers used for monitoring human exposure to lead: advantages, limitations, and future needs. Environ Health Perspect 2005:113:1669-74.

29 Gwini S, MacFarlane E, Del Monaco A, et al. Cancer incidence, mortality, and blood lead levels among workers exposed to inorganic lead. Ann Epidemiol 2012;22:270-6.

30 Liao LM, Friesen MC, Xiang YB, et al. Occupational lead exposure and associations with selected cancers: the Shanghai Men's and Women's Health Study Cohorts. Environ Health Perspect 2016;124:97-103.

31 Vida S, Richardson L, Cardis E, et al. Brain tumours and cigarette smoking: analysis of the INTERPHONE Canada case-control study. Environ Health 2014;13:55.

32 Siemiatycki J, Wacholder S, Dewar R, et al. Smoking and degree of occupational exposure: are internal analyses in cohort studies likely to be confounded by smoking status? Am J Ind Med 1988;13:59-69.

33 Kriebel D, Zeka A, Eisen EA, et al. Quantitative evaluation of the effects of uncontrolled confounding by alcohol and tobacco in occupational Cancer studies. Int $\mathrm{J}$ Epidemiol 2004:33:1040-5.

34 Siemiatycki J, Wacholder S, Dewar R, et al. Degree of confounding Bias related to smoking, ethnic group, and socioeconomic status in estimates of the associations between occupation and Cancer. J Occup Med 1988;30:617-25.

35 Bayer O, Cámara R, Zeissig SR, et al. Occupation and Cancer of the larynx: a systematic review and meta-analysis. Eur Arch Otorhinolaryngol 2016;273:9-20.

36 Steenland K. Laryngeal Cancer incidence among workers exposed to acid mists (United States). Cancer Causes Control 1997:8:34-8.

37 Steenland K, Nowlin S, Ryan B, et al. Use of multiple-cause mortality data in epidemiologic analyses: us rate and proportion files developed by the National Institute for Occupational Safety and Health and the National Cancer institute. Am J Epidemiol 1992;136:855-62.

38 Chowdhury R, Darrow L, McClellan W, et al. Incident ESRD among participants in a lead surveillance program. Am J Kidney Dis 2014;64:25-31. 